\title{
The Defective Character Solution to the Non-Identity Problem
}

\author{
Ben Bramble \\ b.e.bramble@gmail.com
}

Forthcoming in The Journal of Philosophy.

[Pre-review copy. Copyright lies with the Journal of Philosophy.]

The non-identity problem, in a nutshell, is that some actions seem morally wrong even though, by affecting future people's identities, they are worse for nobody. ${ }^{1}$ I will give two well-known examples of such actions, as described by David Boonin. ${ }^{2}$ First:

Wilma. Wilma has decided to have a baby. She goes to her doctor for a checkup and the doctor tells her that... as things now stand, if she conceives, her child will have a disability...that clearly has a substantially negative impact on a person's quality of life...[but is not] so serious as to render the child's life worse than no life at all...[But] Wilma can prevent this from happening. If she takes a tiny pill once a day for two months before conceiving, her child will be perfectly healthy. The pill is easy to take, has no side effects, and will be paid for by her health insurance...Wilma decides that having to take a pill once a day for two months before conceiving is a bit too inconvenient and so chooses to throw the pills away and conceive at once. As a result of this choice, her child is born [with the disability]. ${ }^{3}$

\footnotetext{
${ }^{1}$ The problem was first brought to the attention of philosophers by Derek Parfit in his "On Doing the Best for Our Children," in Michael D. Bayles, ed., Ethics and Population (Cambridge, MA: Schenkman, 1976), pp. 100-115, and further developed in his Reasons and Persons (Oxford: Oxford University Press, 1984).

${ }^{2}$ David Boonin, The Non-Identity Problem and the Ethics of Future People (Oxford: Oxford University Press, 2014). Boonin's cases are based on some of Parfit's own. I use Boonin's descriptions rather than Parfit's or my own, as Boonin's are beautifully succinct and evocative.

${ }^{3}$ Boonin, ibid., 2.
} 
Wilma's action seems morally wrong. But how can it be? It is not, after all, any worse for her child. Had Wilma taken the pills, the particular individual who is now her child would not have existed at all. Instead, a numerically different individual would have existed in her place, since a different sperm-egg combination would have been involved in the conception. Wilma's conceiving immediately, rather than her taking the pills, is not worse for her child, since it was a condition of this particular individual's (worthwhile) existence.

Here is the second example:

The Risky Policy. A wealthy society is running out of the fossil fuels that have made its affluence possible, and is choosing between two sources of energy to replace them. One option is a source of energy that would enable its current citizens to continue to enjoy a high standard of living and which would have no negative impact on future generations. The second option is a source of energy that would enable its current citizens to enjoy a slightly higher standard of living but which would generate a significant amount of toxic waste. The waste could be safely buried for a long period of time, but it is known that after five hundred years, the waste would leak out and that of the millions of people who would be exposed to it, tens of thousands would be killed as a result. [Call] the first option... the safe policy. [Call] the second option...the risky policy...Knowing that the risky policy will generate toxic waste that will eventually leak and kill tens of thousands of innocent people in the future, the current members of the wealthy society nonetheless decide to select that option because doing so will enable them to enjoy a slightly higher quality of life. As a result of their choice, the toxic waste that they create and bury leaks out five hundred years later and kills tens of thousands of innocent people. ${ }^{4}$

The action of the Wealthy People (WP) seems morally wrong. But how can it be? It is not, after all, any worse for those prematurely killed as a result of the toxic waste, since it is a condition of their (worthwhile) existence. Why is it a condition of their existence? Boonin explains this nicely as follows:

The choice of one energy source over the other...will...have an impact on where people decide to work, play, and live, all of which will have an impact on who they meet and when they meet them, which will in turn have an impact on who they decide to have children with, on whether they decide to have any children at all, and so on...Over time, the effects of these subtle differences will be enough to generate two entirely distinct sets of people: the set of people who will exist five hundred years from now if the safe policy is selected, and the completely different

\footnotetext{
${ }^{4}$ Boonin, ibid., 5.
} 
set of people who will exist five hundred years from now if the risky policy is selected. ${ }^{5}$

Many different responses have been given to the non-identity problem. The most popular response has been to try to explain how these actions can be wrong even if they are worse for nobody. It has been argued, for example, that they are wrong because they

(i) harm people without being worse for them ${ }^{6}$,

(ii) wrong people, violate their rights, or exploit them, without harming or being worse for them ${ }^{7}$,

(iii) bring about more pain than pleasure. ${ }^{8}$

Each of these explanations faces serious and well-documented difficulties. $^{9}$

My goal in this paper is to further develop and defend a lesser known solution to the problem, one according to which when such actions are

\footnotetext{
${ }^{5}$ Boonin, ibid., 6.

${ }^{6}$ See, for example, Seana Shiffrin, "Wrongful Life, Procreative Responsibility, and the Significance of Harm," Legal Theory, V, 2 (1999): 117-48; Elizabeth Harman, "Harming as Causing Harm", in Melinda A. Roberts and David T. Wasserman, eds., Harming Future Persons: Ethics, Genetics and the Nonidentity Problem, (New York: Springer, 2009), pp. 137-54; Molly Gardner, “A Harm-Based Solution to the Non-Identity Problem," Ergo, II, 17 (2015): 427-444.

${ }^{7}$ See Gregory Kavka, "The Paradox of Future Individuals," Philosophy and Public Affairs, XI, 2 (1982): 93-112; Doran Smolkin, "Toward a Rights-Based Solution to the Non-Identity Problem," Journal of Social Philosophy, XXX, 1 (1999): 194-208; Rivka Weinberg, "Identifying and Dissolving the Non-Identity Problem," Philosophical Studies, CXXXVII, 1 (2008): 3-18; David Velleman, "Persons in Prospect," Philosophy \& Public Affairs, XXXVI, 3 (2008): 221-322.

${ }^{8}$ For further discussion of (iii), see Parfit, Reasons and Persons, op. cit.

${ }^{9}$ For criticism of (i), see especially Matthew Hanser, "Harming and Procreating," in Melinda A. Roberts and David T. Wasserman, eds., Harming Future Persons: Ethics, Genetics and the Nonidentity Problem (New York: Springer, 2009), pp. 179-199; Judith Thomson, "More on the Metaphysics of Harm," Philosophy and Phenomenological Research, LXXXII, 2 (2010): 438-458; and Ben Bradley, "Doing Away with Harm," Philosophy and Phenomenological Research LXXXV, 2 (2012): 390-412. For criticism of (ii), see especially Parfit, ibid. The best-known and most serious criticism of (iii) is that it gives rise to what Parfit, ibid., dubs the repugnant conclusion.
} 
wrong, it is not because of what they do or produce at all, but rather just because of why they were performed.$^{10}$ In particular, I will argue that

such actions are wrong just when and because they result from, or reflect in those who have performed them, a morally dubious character trait.

Following Boonin, I will refer to this as the defective character solution (DCS). ${ }^{11}$

The plan for the paper is as follows: I will start by motivating DCS (section I). I will then describe what I consider to be the best candidates for the morally dubious traits that, on DCS, explain the moral wrongness of the actions in non-identity cases (section II). I will then respond to two important objections to DCS (sections III and IV). Finally, I will explain what I regard as the second-best solution to the non-identity problem, a view on which the actions in these cases are not morally wrong (section $\mathrm{V})$.

\section{MOTIVATING DCS}

According to DCS, the actions in non-identity cases are morally wrong, not because of what they do or produce, but just when and because they result from or reflect a morally dubious character trait in those who have performed them. To see the appeal of DCS, consider some variations of the non-identity cases where, due to giant flukes, the predicted outcomes do not occur (Wilma's child is not born disabled, and there is no toxic leak). In these variations, the actions of Wilma and WP still seem morally wrong or condemnable, but it is hard to see how they could be wrong

${ }^{10}$ Others who have defended this sort of solution include Valentina Urbanek, The Non-Identity Problem, Dissertation MIT (2010); David Wasserman "The Nonidentity Problem, Disability, and the Role Morality of Prospective Parents," Ethics, CXVI, 1 (2005): 132-52; and Mianna Lotz, "Rethinking Procreation: Why it Matters Why We Have Children," Journal of Applied Philosophy, XXVIII, 2 (2011): 105-21.

${ }^{11}$ Boonin, The Non-Identity Problem and the Ethics of Future People, op. cit., 184. 
because of what they do or produce-after all, the relevant future individuals are completely fine. How, then, are we able to explain their wrongness? A natural thought is that we might be able to do so by appeal to something that remains fixed in both the original cases and the variations: why the actions were performed. Here, we have, I think, a powerful motivation for DCS.

It might be suggested that certain rivals of DCS-namely, deontological accounts-also have the resources to explain why the actions in the variations are wrong. This is because, while these actions are not worse for anyone and so harm nobody, they might nonetheless wrong the relevant future people or breach their rights in some way. ${ }^{12}$ Consider, by analogy, a case where you fail to fasten your child's safety belt, but no accident occurs. Here, it might be said, you have acted wrongly because you wronged your child in some way or breached their rights, even though your child was in no way made worse off or harmed.

But consider a further kind of case, where Wilma attempts to conceive now rather than wait, but a different kind of fluke occurs, preventing conception altogether. Intuitively, what Wilma does in this further case is still morally wrong or condemnable. ${ }^{13}$ Indeed, it seems equally wrong as in the earlier cases. But in this further case, there is no future person at all who might count as wronged by her action. If what she does here is equally wrong as what she does in the earlier cases, then its wrongness in those earlier cases is not plausibly due to its harming or wronging some future individual. It is more plausible to say that it is due to something that remains fixed in all three cases: why the actions were performed.

\footnotetext{
${ }^{12}$ According to Velleman, "Persons in Prospect," op. cit., for example, the actions in non-identity cases are wrong because they breach future people's rights "to be born into good enough circumstances" (275) or "to have been created with due consideration for one's humanity" (276). He writes: "A child to whom we give a lesser initial provision will have been wronged by our lack of due concern for human life in creating him-our lack of concern for human life itself, albeit in his case" (276). ${ }^{13}$ Note that her morally wrong action here is one, not of conceiving (for there is no conception), but of trying to conceive. Was her wrong action in the earlier cases the same-namely, one of trying to conceive, rather than actually conceiving? For the purposes of this paper, I am happy to describe it in either of these terms.
} 
There is a further thing to say in response to the suggestion that the actions in the variations might be wrong because they wrong those whom they create. Even if the people created exist in a wronged state, there is reason to think that they are not wronged by these acts of creation.

Consider the following analogy. Suppose you create somebody who is in a tickled state (when the only alternatives are creating a different individual or nobody at all). It is implausible to say that by creating this person, you have tickled them. The same goes, it seems to me, for wronging a person. Just as you cannot tickle somebody by creating them in a tickled state, you cannot wrong somebody by creating them in a wronged state (again, on the assumption that the alternative was not to create them at all). ${ }^{14}$

\section{THE MORALLY DUBIOUS TRAITS}

What morally dubious traits of Wilma and WP could be explaining why their actions are wrong? There are, I think, several possibilities. To see one possibility, consider that, though the actions of Wilma and WP are not worse for anybody, and so harm nobody, Wilma and WP might not realise this, and indeed might believe that their actions would harm the relevant future people. How might they believe this? One way is if they hold the mistaken view that the relevant future people are in some sense 'waiting in the wings', or fixed in their identities prior to conception. They might hold this view, for example, if they do not realise that changing the time of conception changes the sperm-egg combinations that give rise to future people. Alternatively, they might hold this view if they do not realise that changes in sperm-egg combinations have a bearing on identity.

\footnotetext{
${ }^{14}$ For a similar idea, see Hanser, "Harming and Procreating," op. cit., 195. Hanser writes, of a case like that of Wilma, "The parents' creating their child rather than doing something else does not explain why their child has one sort of life or existence rather than another...Their creating him rather than doing something else explains why he is alive rather than not alive, existent rather than nonexistent. The bare property of being alive, or of existing, however, does not have both good and bad "elements"".
} 
Another way that Wilma and WP might believe that their actions would harm the relevant future people is if they do not realise that harming someone requires making that person worse off in some respect than they would otherwise have been. If they do not realise this, then they might believe that their actions would harm the relevant future people even if they understand that conception time affects sperm-egg combination, and sperm-egg combination affects identity.

If Wilma and WP believe that their actions would harm the relevant future people, then their actions might be wrong in virtue of expressing or reflecting in Wilma and WP a morally dubious willingness to harm others for the sake of relatively minor or trivial gains for themselves.

Turn now to the second possibility. Wilma and WP might not have even considered whether their actions would harm the relevant future people. Though Wilma has been told that her child would have a disability, and WP have been told that there would be a toxic leak, it might not have occurred to them that these things could harm the future people in question. This is because they might be too caught up in their own affairs or too focused on possible gains for themselves. In this case, their moral flaw would be, not a willingness to harm others for the sake of relatively minor or trivial gains for themselves, but a simple failure to think of others in the first place. It might be that if they were disposed to think more about othersand in particular of the impacts of their actions on others' well-beingthey would form the belief (albeit mistaken) that their actions would harm the relevant future people, and on this basis refrain from performing the actions in question. Here, their actions would be wrong in virtue of expressing their self-absorption.

Turn now to the third possibility. Suppose these agents

(1) understand that their choice of action will affect the identities of relevant future people, and so that their proposed action (for example, conceiving now, enacting the risky policy, and so on) would not harm future individuals, and 
(2) perform these actions only because of this understanding (that is, without it, they would not perform these actions, out of a concern for the relevant future individuals).

Call these amended agents Wilma* and $\mathrm{WP}^{*}$. Their actions still seem wrong. But what could their morally dubious traits be? ${ }^{15}$ The remainder of this section will be devoted to answering this question.

Consider, first, Wilma*. Suppose she is at the doctor's, where a trainee who happens to have studied population ethics is observing. Their conversation goes like this:

Doctor: Wilma, I'm sorry to tell you that if you conceive now, your child will have a serious disability.

Wilma*: Oh no, doctor, that's terrible news!

Doctor: Don't worry. If you take these pills every day for two months, and then conceive, your child will be born completely healthy.

Wilma*: That's a relief! I have a very busy next two months and it will be inconvenient to take these pills, but of course I'm happy to take them to improve my child's life.

Trainee: I'm sorry to interrupt, but I feel I should point out that if you wait two months, this would change the identity of your child. A different sperm-egg combination would be involved in the conception. So, waiting would not actually be better for your child (at least not in the sense that matters). Similarly, conceiving now would not be worse for the individual you give birth to. In fact, it is this individual's only chance of existing at all.

Wilma*: Gosh, how interesting. Of course, you're right. What fabulous news! I've no need to take the pills. I'll conceive immediately.

\footnotetext{
${ }^{15}$ Boonin believes that this is a question DCS cannot answer. See Boonin, The NonIdentity Problem and the Ethics of Future People, op. cit., 185-88.
} 
There is, it seems to me, still something disturbing about Wilma*, even though she is neither self-absorbed nor prepared to do what would be worse for her child for the sake of trivial gains for herself. What is disturbing about her? Wilma*, it seems, is emotionally or affectively cold in a certain way. A normal person in her situation would simply mind the thought of their child's having a serious disability-that is, they would have a negative emotional reaction (including some unpleasant feelings) to this thought-even after hearing and understanding what the trainee doctor had said. At the very least, they would be aware, if only implicitly, that their child's having such a disability would be significantly worse for them-say, by causing them to feel some sadness or upset each day that they would not otherwise feel, at witnessing the difficulties faced by their child. For this reason, they would not hesitate to wait two months, despite the inconvenience of this.

Suppose Wilma* is indeed cold in this way. Why is such coldness disturbing, rather than merely abnormal or unusual? The answer, I want to suggest, is that such coldness interferes with a person's ability to experience some of the best things in life-most notably, deep and close personal relationships, and appreciation of great works of art. ${ }^{16}$ To fully experience these things, one needs to have a kind or depth of emotionality that Wilma* (on my supposition) lacks. Someone who does not feel sad at the thought of their child's having a serious disability (even where this disability is a condition of this child's very existence) is not somebody who is going to be able to have the full range of beneficial emotional responses to things.

\footnotetext{
${ }^{16}$ I assume here the existence of certain objective personal goods- that is, things that are good for us, or that contribute to our well-being, whether we want them or not. This, of course, is a controversial assumption, and I've not space to defend it here. I will note only that the goods I am appealing to-personal relationships and appreciation of great works-are among the least controversial such goods in the literature. Most objective list theorists are happy to include them, or similar items, on their lists of goods. For more on objective theories, see Guy Fletcher, "A Fresh Start for the Objective-List Theory of Well-Being," Utilitas, XXV, 2 (2013): 206-220.
} 
Wilma* is disturbing, in other words, because we implicitly realise that she is someone who, in virtue of her coldness, is cut off from the full range of beneficial human experiences. Part of our concern here is for her (or for her level of well-being). But part of it seems also to be that she reminds us of the possibility of a world in which people more generally are colder or less emotional than they are in the actual world right now, and so a world in which people's lives are much less valuable for them than they are in reality. This is disturbing because it reminds us of the contingency-and indeed the fragility - of much that is valuable in our world. It reminds us not only that things might be otherwise, but that they might yet come to be otherwise, a terrifying prospect.

Now, why might Wilma* be, not simply disturbing, but morally so? It is, I want now to suggest, because a person's emotional responses-and indeed their emotional responsiveness more generally-can be infectious or catching. The ways that people feel about things are constantly forming and reforming, a process that is heavily influenced by their perceptions of the feelings of others. In the psychological literature, this phenomenon is known as emotional contagion. ${ }^{17}$ We are especially influenced by the emotions of our immediate peers, whether family, friends, or colleagues, and in particular those who seem to us most significant or powerful within these groups. Importantly for my purposes, this process takes place mostly unconsciously. ${ }^{18}$

Wilma*, then, might be morally dubious in virtue of having a tendency, through her words, deeds, or even mannerisms, to lead others to become colder themselves, thereby harming them (by interferring with their ability to experience some of the best things in life). A perfect example is

\footnotetext{
${ }^{17}$ See especially Elaine Hatfield, John T. Cacioppo, and Richard L. Rapson, "Emotional Contagion," Current Directions in Psychological Science, II, 3 (1993): 96-99. For related sociological literature, see Randall Collin, "Stratification, Emotional Energy, and the Transient Emotions," in T. David Kemper, ed., Research Agendas in the Sociology of Emotions (State University of New York Press, 1990), pp. 27-57; and David R. Heise and J. O'Brien, "Emotion Expression in Groups", in Michael Lewis and Jeannette M. Haviland, Handbook of Emotions (New York: Guilford, 1993), pp. 489-497. ${ }^{18}$ Hatfield et al, ibid.
} 
her decision to conceive now rather than wait. This decision, by revealing her to not feel sad about her child's having a serious disability, might influence others whom she encounters to become less emotional when they contemplate similar outcomes. Alternatively, it might make a small contribution to a gradual normalisation in society of such unemotionality, a sense that such unemotionality or coldness is neither abnormal nor harmful to its subject. This in turn could lead to others becoming colder, or, in the case of those who are already cold, to their failing to recover or achieve warmth.

It might be objected: but Wilma* might not even realise she is cold in a way that interferes with her ability to experience some of the best things in life. Alternatively, she might not realise that her words and deeds have a tendency to lead others to become colder themselves. If either of these things is true, then she cannot rightly be considered morally dubious even if she has a tendency to harm others in this way.

I disagree. Even if Wilma* does not realise these things, it might be that she should realise them. She might be, for example, 'in denial' about her unemotionality or its harmfulness to herself and (potentially) to others, perhaps out of an unconscious recognition of the pain that acknowledging these things might cause her, or the burdens she would thereby acquire (burdens to, for example, curtail her behaviour, feign warmth, or even possibly quarantine herself from others in certain contexts). ${ }^{19}$ Even if she is not in some sense in denial, she might nonetheless be smart enough that she should realise these things and amend her behaviour accordingly. ${ }^{20}$

But perhaps Wilma* is not cold. She might feel sad indeed at the thought of her child's having such a disability, yet conceives now out of hard-headedness. She thinks to herself:

\footnotetext{
${ }^{19}$ Or perhaps someone who is cold like Wilma* should simply be upfront about her lack of emotion, and her concern that it might reduce her own well-being or that of others.

${ }^{20}$ Note that if Wilma* is entirely lacking in emotion (or even perhaps in certain ways seriously bereft of it) she might not count as morally evaluable at all. Some emotionality, arguably, is needed for this.
} 
My feelings of sadness here are inappropriate or ill-fitting. They do not reflect the normative reality of my situation-namely, that conceiving now would be in no way worse for my child. I have no reason to have such feelings. Given this, I should attach them no weight or significance. I should ignore or even oppose them.

Call this woman Wilma**. Might Wilma** still be morally disturbing? I think so. Suppose she is right that her feelings of sadness are inappropriate or ill-fitting. ${ }^{21}$ Still, the fact that she is disposed to feel them entails that it is hugely imprudent for her to conceive now rather than wait. She is choosing a course that will be considerably worse, on balance, for herself, and better for no one.

It might be suggested that Wilma** might think that choosing this course could help her to 'harden up' emotionally, and so to experience such ill-fitting feelings less often. But if this is true, then she is even less prudent, for she is trying to rid herself of (or at least diminish) what is a condition of many of the best things in her life.

If Wilma** is imprudent in either or both of these ways, then she is, I believe, like the version of Wilma* who is emotionally cold, a kind of threat to others, for her words and deeds might incline some others to become less emotional themselves, or to make choices that are worse for them and better for no one (by leading to outcomes where they often feel sad).

Incidentally, it seems doubtful that Wilma** is right that her feelings of sadness are inappropriate or ill-fitting. While her conceiving now rather than later would not be worse for her child, if she does conceive now, then her child's disability will be worse for it. Her child will be worse off living with this disability than it would be were it to somehow exist without it. Wilma**'s feelings of sadness (whether she realises it or not) are almost certainly at the thought of her child's having this disability as opposed to

\footnotetext{
${ }^{21}$ In a moment I will question this assumption.
} 
this very same individual's existing without this disability. ${ }^{22}$ Certainly, if she were to conceive now, then the feelings of sadness she would experience during her time as a parent would be at the thought of her child's having this disability as opposed to this very same individual's existing without this disability. ${ }^{23}$

Turn now to $\mathrm{WP}^{*}$. Imagine the following conversation taking place between several members of the wealthy society:

Alex: We should enact the safe policy. We must take into account the interests of these future people. Our being slightly better off now is not worth their suffering in this way.

Bella: I totally agree.

Caleb: I'm sorry to interrupt, but I've studied population ethics. Do you realise that our choice of policy here will affect the identities of these future people? Given this, enacting the risky policy would not be worse for any of these future people. On the contrary, it is their only chance of existing.

Alex: Gosh, how interesting. Of course, you're right. What fabulous news! I now think we should enact the risky policy. This would enable us to be better off at no one's expense.

Caleb: My thoughts precisely.

Bella: Hold on, you two! Don't you just mind the thought of the future containing all this suffering, of this being the future course of the world? Isn't this thought unpleasant to you? Doesn't it make you feel sad or upset?

Alex: Not at all.

Caleb: Me neither.

\footnotetext{
${ }^{22}$ It is hard to imagine what it would even be for one to feel sad right now at the thought of one's conceiving now and having a disabled child as compared with one's waiting two months and then having a healthy child.

${ }^{23}$ Note that, if what I've said here is right, this adds a further dimension to my worry about Wilma*'s coldness. It means that she is not responding in a way that is fitting, or called for by the normative reality of her situation. This might constitute a further respect in which she is disturbing (even if not morally so).
} 
Again, there seems something disturbing here about Alex and Caleb. As Bella realises, they seem to be cold in a certain way. Someone who is emotionally as one needs to be in order to fully experience the best things in life would, as a matter of fact, feel sad at the thought of future people suffering in these ways, even if they recognised that this suffering was, in the relevant circumstances, a necessary condition of these individuals' existing at all. The responses of Alex and Caleb suggest that they cannot fully experience these best things in life. And they are morally disturbing because they seem cavalier here, liable to speak or act in ways that might have a tendency to lead some others in society to come to feel colder-say, their own children, friends, colleagues, and so on. Alex and Caleb should know better.

But suppose Alex and Caleb respond to Bella's challenge in a different way. They say:

Yes, of course the thought of all this suffering in future times makes us feel sad. But it should not do so. Such feelings are ill-fitting. There is no reason to have them.

Call members of the wealthy society who respond this way to Bella's challenge, $W P^{* *}$. Might $W P^{* *}$ still be morally dubious? I think so. Whether or not such feelings of sadness are ill-fitting ${ }^{24}$, they make life significantly worse for those who feel them. Alex and Caleb should realise that they themselves would be better off if the safe policy were enacted, and so this future suffering was not predicted to occur. They are morally dubious because, like Wilma**, their words and deeds might lead to others becoming less emotional themselves or making choices that are worse for them and better for no one. And if Alex and Caleb are in addition hoping, by advocating the risky policy, to themselves 'harden up', then they pose an even greater threat to others who might be influenced by them.

${ }^{24}$ And, as I suggested above, this is disputable. 
I conclude that Wilma* and $\mathrm{WP}^{*}$ might be morally dubious in virtue of being cold or imprudent in ways that have a tendency to spread to others, and so harm other people. This might account for the wrongness of their actions.

\section{THE ‘NO REASONS' OBJECTION}

I want now to consider two important objections to DCS. The first objection is that, intuitively, the wrongness of these actions provides Wilma and WP with reasons not to perform these actions, and forwardlooking reasons at that - that is, reasons having to do precisely with what these actions would do or produce. But DCS cannot account for this, as it locates the wrongness of these actions in what they say about Wilma and WP. This relation could not constitute a reason (or at any rate, not the right kind of reason). By contrast, the rival explanations of these actions' wrongness mentioned in the introduction face no such worry. Unlike DCS, they can say that these agents have reasons not to perform these actions stemming from what these actions do or produce-for example, from their harming future beings, wronging future beings, or bringing about more pain than pleasure.

The first thing to say in response to this objection is that DCS can account for why at least many of the agents in non-identity cases have forward-looking reasons not to perform the actions in question. It can do so because, as I've been arguing, their performing these actions might be worse for some existing people. Wilma* and WP* (including Wilma** and $\mathrm{WP}^{* *}$ ) might influence some others to become colder or less prudent in various ways. As for Wilma and WP, they might influence some others to come to have less regard for other people, which (for obvious reasons) could be worse in various ways for these latter people.

It might be objected that even if this is true, the reasons in question would not stem from the wrongness of the actions per se. But this is not so. If DCS is true, then there would be a clear sense in which these reasons are connected with these actions' wrongness. On DCS, their wrongness 
consists in the fact that these agents threaten harm to others. As for the forward-looking reasons they have not to perform these actions, these are reasons to avoid precisely these harms.

Indeed, it might be thought that DCS here has an advantage over the rival explanations of these actions' wrongness, for only DCS links the reasons these agents have not to perform these actions to these actions being worse for certain beings. Why is this an advantage? It is because an action's being worse for someone is more clearly a reason not to perform it than is its, say, harming, wronging, or causing more pain than pleasure, without being worse for anyone.

It might be objected that this response is inadequate, since it is important that the reasons these agents have to avoid the actions in question be even more strongly related to their wrongness. In particular, it is necessary that their being wrong is sufficient for (or a guarantee of) the existence of such reasons.

But I do not see why this is so. What seems intuitive here (to me, at least) is just that in such cases there are generally forward-looking reasons not to perform such actions. That, on DCS, there are some unusual cases in which such reasons do not exist-that is, cases where these actions happen not to influence anybody to become colder, less prudent, and so on-does not seem to me to be a problem for DCS. Indeed, when we consider such cases, it seems to me intuitive that there are no such reasons in them. Suppose, for example, that Wilma* lives a fairly solitary existence, and so happens through good fortune not to influence anyone to become any colder themselves. Furthermore, had she waited to conceive, this would, as a matter of fact, not have led her to become any less cold herself. In such a case, Wilma* might still, on DCS, be morally dubious, and her action wrong (in virtue of reflecting her dubiousness), but it does not seem plausible to me that she in fact had a reason to wait. ${ }^{25}$

\footnotetext{
${ }^{25}$ I admit that it might be hard, in such hypotheticals, to have clear intuitions. But this, it seems, is a point in my favour, for it would mean that it is harder also to have clear intuitions that Wilma* has a reason.
} 


\section{THE ‘FOUNDING INTUITION’ OBJECTION}

The non-identity problem is founded on the fact that so many people find intuitive the following principle:

WRONGNESS. An action is morally wrong only if it is worse for somebody. ${ }^{26}$

If DCS is right, however-or indeed, if any of the other explanations mentioned in the introduction of why the actions in such cases are morally wrong is right-then WRONGNESS is false. DCS, then, like these other explanations, owes us an account of why so many people find WRONGNESS intuitive when it is in fact false. The difficulty of providing such an account is the second objection to DCS I want to consider.

Why do so many people find WRONGNESS intuitive? There are, I think, two main reasons. The first is that, since DCS is true, the vast majority of actions that are morally wrong are worse for some beings. As I've been arguing, the actions in non-identity cases that are morally wrong reveal the agent in question to be in some way dangerous or threatening to others. Actions that reveal or express such a trait will naturally be, in many cases, in fact worse for certain others.

As I've said, there are exceptions, unusual cases in which an action might express or reflect the agent's having a tendency to perform actions that are worse for others, but not in fact be worse for anyone. But a proponent of DCS can say that the connection here is strong enough that it might be part of the explanation for why people find WRONGNESS intuitive. People are here picking up on this general truth, and mistaking it for a hard and fast rule.

\footnotetext{
${ }^{26}$ Parfit calls such a principle the Narrow Deontic (Person-Affecting) Principle in his "Future People, the Non-Identity Problem, and Person-Affecting Principles," Philosophy \& Public Affairs, XLV, 2 (2017): 118-157.
} 
The second reason for which some people might find WRONGNESS intuitive when it is in fact false is that there is a related principle that is true, namely:

REASONS. One has a reason not to perform an action only if it is worse for somebody.

Perhaps some people who find WRONGNESS intuitive are picking up instead on the truth of REASONS. This could easily be so given that many people seem to assume-wrongly, as I've been arguing — that if an action is morally wrong there must be some reason not to perform it. If it were true that an action's being wrong guaranteed a reason not to perform it, then the truth of REASONS would indeed entail the truth of WRONGNESS.

This proposed explanation is supported by the apparent fact that when people come to accept that the wrongness of an action does not entail the existence of some reason not to perform it, they tend no longer to find WRONGNESS so intuitive. It is, ultimately, I think, just the truth of REASONS that so many of us are, on reflection, so keen to insist upon.

\section{THE SECOND-BEST SOLUTION}

I've been arguing that DCS is the right solution to the non-identity problem. But there is a different possible solution that seems to me to have almost as much to recommend it. On some days, I am tempted to think that it (rather than DCS) is the correct solution.

A good way to bring out the basic idea of this second-best solution is to return to a classic paper by Thomas Hill Jr.. In this paper, Hill considers some other kinds of cases (that is, not non-identity cases) where certain 
actions seem morally wrong even though they are not worse for anyone. ${ }^{27}$ He asks us to consider, for example:

The Asphalter. A wealthy eccentric bought a house...surrounded by a beautiful display of grass, plants, and flowers, and...shaded by a huge old avocado tree. But the grass required cutting, the flowers needed tending, and the man wanted more sun. So he cut the whole lot down and covered the yard with asphalt. After all it was his property and he was not fond of plants. ${ }^{28}$

\section{Suppose the house was tucked away so that no passersby were made} worse off as a result of no longer getting to see the garden. Suppose further that The Asphalter cut down the garden only on this conditionhe might even have been a kind of effective altruist, determined not to make others worse off. Still, many of us report having a negative moral reaction to what he has done. According to Hill, our concern here is not necessarily with his action itself-which, Hill says, might not be morally wrong, given that it in fact does not harm anyone. Instead, it might be just with his character, and his moral character at that. Hill writes:

Rather than argue directly with destroyers of the environment who say, "Show me why what I am doing is immoral," I want to ask, "What sort of person would want to do what they propose?" The point is not to skirt the issue with an ad hominem, but to raise a different moral question, for even if there is no convincing way to show that the destructive acts are wrong (independently of human and animal use and enjoyment), we may find that the willingness to indulge in them reflects the absence of human traits that we admire and regard morally important. ${ }^{29}$

\section{He continues:}

Sometimes we may not regard an act wrong at all though we see it as reflecting something objectionable about the person who does it. Imagine, for example, one who laughs spontaneously to himself when he reads a newspaper account of a plane crash that kills hundreds. Or, again, consider an obsequious grandson who, having waited for his grandmother's inheritance with mock devotion, then secretly spits on her grave when at last she dies. Spitting on the grave may have no adverse consequences and perhaps it violates no rights. The moral uneasiness which it arouses is explained more by our view of the agent than by any conviction that what he did was immoral. Had he hesitated and asked, "Why shouldn't I spit on her grave?", it seems more fitting to ask him to reflect on the

\footnotetext{
${ }^{27}$ Thomas E. Hill, Jr. "Ideals of Human Excellence and Preserving Natural Environments," Environmental Ethics, V, 3 (1983): 211-24.

${ }^{28}$ Hill, ibid., 213.

${ }^{29}$ Hill, ibid., 217. My emphasis.
} 
sort of person he is than to try to offer reasons why he should refrain from spitting. ${ }^{30}$

A similar line can be mounted, I believe, and with considerable plausibility, in response to non-identity cases. We can say that our negative moral response in such cases is one, not to the actions of these agents, but strictly to their character. Their actions, we can say, are not morally wrong at all. It is only that those who performed them are morally dubious in certain ways. How are they morally dubious? In the ways, say, I've outlined earlier in this paper. ${ }^{31}$

Now, of course, I am hardly the first to see that it might be an option to deny that the actions of these agents are morally wrong. This response already has some important advocates-most notably, Boonin himself, as well as David Heyd. ${ }^{32}$ But the particular solution I'm suggesting as the second-best solution has a distinct advantage over the accounts of Boonin and Heyd, for it makes possible a better explanation of why we might be tempted to think that the actions in the non-identity cases are morally wrong, even though they are not wrong. On my proposed second-best solution, unlike on the accounts of Boonin and Heyd, we can say that we are picking up here on the morally dubious character of these people, and this is leading us to mistakenly infer or insist upon the moral wrongness of their actions.

Finally, I want to say a few words about how my proposed second-best solution compares with DCS. Ultimately, I find DCS more compelling because I find it highly intuitive that in non-identity cases, it is not only the agents' character that is morally dubious, but their actions as well. The ability of DCS to vindicate this judgment seems to me a considerable advantage of it.

\footnotetext{
${ }^{30}$ Hill, ibid., 218.

${ }^{31}$ Hill might give a different explanation of these ways, but I will not speculate on what he would say here.

${ }^{32}$ Boonin, The Non-Identity Problem and the Ethics of Future People, op. cit.; David Heyd, "Procreation and Value: Can Ethics Deal with Futurity Problems?," Philosophia, XVIII, 2-3 (1988): 151-70.
} 
But perhaps the right thing to say is that the choice between DCS and my proposed second-best solution is really immaterial. The crucial thing to emphasise in responding to non-identity cases is that

(1) our fundamental negative moral reaction here is to the character of these agents, and

(2) we can account for these agents' having morally dubious character traits (ones that their actions might reflect or express) even if these actions are not worse for anyone.

Whether we should go from here to morally condemning the actions themselves is perhaps an unimportant matter.

\section{CONCLUSION}

In this paper, I have argued that the actions in non-identity cases are morally wrong just when and because they result from, or reflect in those who have performed them, a morally dubious character trait. How can they result from a morally dubious character trait if they are not worse for anyone? It is because the relevant agents might (i) mistakenly believe that their actions would harm some future people (in one or more of the ways described above), (ii) fail to have adequately considered whether their actions would harm some future people, or (iii) be cold or imprudent in ways that might spread to others. 